\title{
Accelerated or hyperfractionated radiotherapy for esophageal carcinoma: a meta-analysis of randomized controlled trials
}

This article was published in the following Dove Press journal:

OncoTargets and Therapy

13 June 2017

Number of times this article has been viewed

\section{Yingyu Liu' \\ Changgui Kou' \\ Yingying $\mathrm{Su}^{\prime}$ \\ Yangyu Zhang' \\ Yueyue You' \\ Lili Zhang' \\ Mohan Wang' \\ Yingli Fu' \\ Xiaojun Ren ${ }^{2}$ \\ Yanming Yang ${ }^{2}$}

'Department of Epidemiology and Biostatistics, School of Public Health, Jilin University, ${ }^{2}$ Department of Radiotherapy, Second Hospital of Jilin University, Changchun, Jilin, People's Republic of China
Correspondence: Yanming Yang

Department of Radiotherapy, Second Hospital of Jilin University, 218 Ziqiang Street, Changchun, I3002I, jilin, People's Republic of China

Tel +86 43188796179

Emailyym180@I63.com
Objective: The goal of this study was to evaluate the efficacy and safety of modified (accelerated and/or hyperfractionated) radiotherapy in the treatment of esophageal carcinoma, compared with conventional radiotherapy.

Methods: Studies published in the PubMed, Cochrane Library, EMBASE, CBM, VIP, CNKI and Wanfang databases in the most recent two decades were searched for use in this meta-analysis. Only randomized controlled trials were included. The heterogeneity analysis and calculation of the pooled odds ratio (OR) were performed using RevMan 5.3 software. The assessment of publication bias and sensitivity analyses was conducted using Stata 13.0 software.

Results: Twenty trials with a total of 1,742 Chinese patients who met the inclusion criteria were included. The pooled results showed that modified radiotherapy improved the response rate compared with conventional schedules ( $\mathrm{OR}=3.90,95 \%$ confidence interval $[\mathrm{CI}]$ : 2.47-6.16, $P<0.001)$. Favorable results were observed for the 1-year (OR $=2.58,95 \%$ CI: 2.05-3.26, $P<0.001)$, 3-year (OR $=2.30,95 \% \mathrm{CI}: 1.83-2.89, P<0.001)$ and 5 -year $(\mathrm{OR}=2.36,95 \%$ CI: 1.74-3.21, $P<0.001)$ overall survival and for the 1-year (OR $=2.46,95 \%$ CI: $1.72-3.51$, $P<0.001$ ), 3-year (OR $=2.08,95 \%$ CI: $1.49-2.90, P<0.001)$ and 5 -year $(\mathrm{OR}=2.15,95 \% \mathrm{CI}$ : $1.38-3.34, P<0.001)$ overall local control rate in the modified fractionation radiotherapy group. However, the altered radiotherapy increased the risk of acute radiation esophagitis $(\mathrm{OR}=1.70$, 95\% CI: $1.27-2.28, P<0.001)$ and acute radiation tracheitis (OR $=1.47,95 \% \mathrm{CI}: 1.09-1.99$, $P=0.01)$. No significant differences in the risk of esophageal perforation ( $\mathrm{OR}=1.30,95 \% \mathrm{CI}$ : $0.51-3.32, P=0.58$ ) or esophagorrhagia ( $\mathrm{OR}=0.88,95 \% \mathrm{CI}$ : $0.41-1.88, P=0.74)$ were found between the two groups.

Conclusion: Chinese patients with squamous cell esophagus carcinomas gained a significant benefit in terms of the response rate, survival and local control rates from the modified fractionation radiotherapy, but also had an increased risk of acute radiation reactions. Otherwise, there was no observed statistically significant difference in terms of early adverse reactions.

Keywords: esophageal carcinoma, radiotherapy, fractionation, meta-analysis

\section{Introduction}

Esophageal carcinoma is the eighth most common malignant tumor, with $>4.5$ million new cases diagnosed every year, and it is the sixth leading cause of cancer-related deaths worldwide, causing $\sim 400,000$ deaths annually. ${ }^{1}$ The occurrences of esophageal cancer tend to follow a geographic distribution. The high-risk areas are also known collectively as the "esophageal cancer belt", which is located from northern Iran to North Central China and accounts for $\sim 90 \%$ of esophageal squamous cell carcinoma cases. $^{2-4}$ 
Esophageal cancer is difficult to detect in its early stages; as a result, patients often present at the time of diagnosis with locally advanced stages or suffer from metastatic disease that may have progressed to lymphatic and hematogenous dissemination. Therefore, radiotherapy (RT) and chemotherapy (CT) have gradually become the most common and necessary treatment in esophageal carcinoma, although surgery is considered as the most effective treatment. ${ }^{5}$ Conventional RT is usually delivered at 1.8-2.0 Gy per fraction once a day from Monday through Friday every week. However, the results for conventional $\mathrm{RT}$ are unsatisfactory, with a 5 -year survival of $\sim 5 \%-10 \%,{ }^{6-8}$ which has led us to explore and investigate new therapeutic strategies. In recent years, two types of modified RT have been studied: the hyperfractionation $(\mathrm{HF})$ regime, with two or three fractions given per day with a 4-6 h interval between fractions and a decreasing dose per fraction, and accelerated RT, with a higher dose in a shorter overall treatment time that is usually combined with HF. ${ }^{9-12}$ Considerable interest has arisen in the comparison between altered fractionated RT and other therapeutic strategies among multiple malignancies in recent years. ${ }^{13-17}$

Unconventional fractionated RT has been applied to treat patients with esophageal carcinoma since the 1980s, and several trials have studied the role of accelerated or hyperfractionated RT in esophageal cancer, providing promising but conflicting results; therefore, this meta-analysis aimed to systematically and accurately estimate the efficacy and toxicity of accelerated or hyperfractionated RT and provide a clearer understanding, with the aid of greater statistical power and more precise results, of the significance of each of these modalities in the treatment of esophageal cancer.

\section{Materials and methods}

\section{Search strategy}

A computerized retrieval of studies was performed by searching the PubMed, Cochrane Library, EMBASE, CBM, VIP, CNKI and Wanfang databases for the most recent two decades (January 1, 1996 to December 31, 2015). There was no limit on the language. The key words used were "esophageal neoplasms", "radiotherapy", "accelerat*", "hyperfraction*" and "random*". The retrieval was adjusted based on the specific database, and all retrieval strategies were confirmed after multiple pre-retrieval tests of the combination of subject words and free words.

\section{Inclusion and exclusion criteria}

To be eligible, trials were required to meet the following inclusion criteria: 1) study design: randomized controlled trials (RCTs); 2) study objective: patients with squamous cell carcinoma of the esophagus and no distant metastases and a Karnofsky performance scale (KPS) score $\geq 60$; 3) study intervention: comparison of modified RT (accelerated or/and hyperfractionated) with conventional RT (1.8-2 Gy fraction per day for 5 days/week with a total dose of 40-70 Gy). Trials of RT using combined CT were included only when the CT schedule and doses were consistent in the two arms; and 4) outcome parameters: response rate (complete remission plus partial remission, classified according to the Response Evaluation Criteria in Solid Tumors $)^{18}$ as an index to evaluate the short-term efficacy; 1-, 3- and 5-year overall survival (OS) and 1-, 3- and 5-year local control rates as indexes to measure the long-term efficacy; acute toxicity included acute radiation reactions (esophagitis and tracheitis) and early adverse reactions (esophageal perforation and esophagorrhagia).

Articles were excluded if 1) they were unrelated or repeated studies found in the literature; 2) they did not offer essential or clear information; 3) they were confounded by additional therapeutic differences, such as adjuvant CT or salvage resection, between the two arms; 4) they focused on a special population, such as the elderly or ethnic minority groups; and 5) an escalated dose of modified fractionation RT was administered.

\section{Data extraction and quality assessment}

Two review authors independently extracted and then crosschecked the recorded data; disagreements were resolved by discussion. Data extraction forms included the following information: the first author, publication year, patients' characteristics, number of patients, details of the intervention and the outcome parameters.

According to the Cochrane Handbook for Systematic Reviews of Interventions (Version 5.1.0), ${ }^{19}$ only the studies that met methodological quality criteria $\mathrm{A}$ (adequate randomization) or B (only trials that were stated to be randomized without further details) were included.

\section{Statistical method and analyses}

The statistical analyses of this meta-analysis were performed using RevMan version 5.3 software. We conducted an analysis for heterogeneity prior to calculating the pooled odds ratios (ORs) with 95\% confidence intervals (95\% CIs) for dichotomous variables. Statistical heterogeneity was assessed using Cochran's chi-square tests. If there was no substantial statistical heterogeneity $\left(P>0.05, I^{2} \leq 50 \%\right)$, data were combined by the fixed-effect model (Mantel and Haenszel methods); otherwise, the heterogeneity was evaluated by 
the random-effect model (DerSimonian and Laird methods). Publication bias was measured by observing the symmetry of the funnel plots, and Egger's test was used to analyze and explore the data. $P \leq 0.05$ was considered statistically significant. A sensitivity analysis was also performed. The publication bias assessment and sensitivity analysis were conducted using STATA version 13.0 software.

\section{Results}

\section{Selection and characteristics of eligible studies}

Our initial search strategy identified 1,058 studies: 41 from PubMed, 11 from Cochrane Library, 49 from EMBASE, 124 from CBM, 241 from VIP, 337 from CNKI and 253 from the Wanfang databases. After screening the titles, abstracts and full text, 1,038 trials were excluded due to duplication or not meeting the inclusion criteria. As shown in Figure 1, 20 articles were included in the final meta-analysis. Among the included studies, only four studies reported details of adequate randomization. The other trials did not provide details of the randomization.

A description of each of the included trials is summarized in Table 1. This meta-analysis included 1,742 Chinese patients (1,152 male, 590 female). There were 858 cases in the modified RT group and 884 cases in the conventional RT group. The patients' genders were well matched between the two randomization arms. The ages of the patients were fairly similar among the studies, ranging from 31 to 77 years old. The KPS scores of the included studies were $>60$, and the lesion lengths were mostly $\leq 10 \mathrm{~cm}$. Of the included studies, 3 compared accelerated fractionation (AF) RT with conventional fractionation (CF) RT, 7 compared HF RT with CF and 10 compared continuous accelerated HF RT with CF. Only one included trial comparing continuous accelerated HF with CF employed CT as a sequential treatment to RT, but there were no studies in the literature that reported RT combined with concurrent CT.

\section{Short-term efficacy}

Six trials were available for inclusion in the evaluation of the short-term efficacy of the response rate (complete remission plus partial remission). There was no evidence of heterogeneity between the two arms $\left(P=0.97, I^{2}=0.0 \%\right)$. Thus, the fixed-effects model (Mantel and Haenszel methods) was selected for the pooled analysis. The meta-analysis showed that there was a significant advantage in the modified RT group compared with the conventional RT group $(\mathrm{OR}=3.90$, 95\% CI: 2.47-6.16, $P<0.001$; Figure 2).

\section{Long-term efficacy}

Analysis of the 1-year survival was based on 1,379 cases from 14 RCTs. The results, which were obtained using a fixed-effects model with a low risk of heterogeneity $\left(P=0.89, I^{2}=0.0 \%\right)$, suggested that the modified RT improved the 1 -year survival $(\mathrm{OR}=2.58,95 \% \mathrm{CI}: 2.05-3.26$, $P<0.001$; Figure 3A). For the 3-year survival, the metaanalysis from 15 trials showed a statistically significant difference that favored the modified RT therapy $(\mathrm{OR}=2.30$,

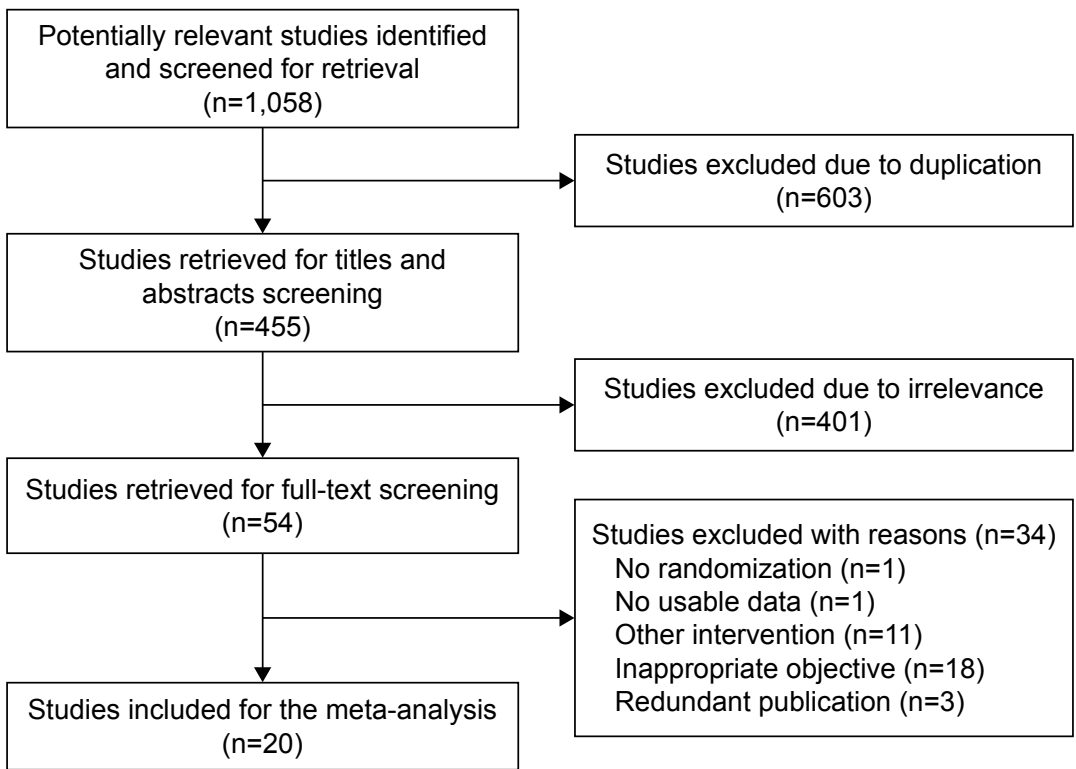

Figure I Search flow diagram for the meta-analysis. 
Table I Description of baseline characteristics included trials

\begin{tabular}{|c|c|c|c|c|c|c|c|c|c|c|}
\hline References & $\begin{array}{l}\text { Age } \\
\text { (years) }\end{array}$ & KPS & $\begin{array}{l}\text { Lesion } \\
\text { length } \\
(\mathrm{cm})\end{array}$ & $\begin{array}{l}\text { Inclusion } \\
\text { period* }\end{array}$ & $\begin{array}{l}\text { Quality } \\
\text { assessment }\end{array}$ & Arms & Subjects (n) & $\begin{array}{l}\text { Number of } \\
\text { fractions }\end{array}$ & Dose (Gy) & Duration \\
\hline Sun et al & $\leq 75$ & $\geq 70$ & $3-10$ & $2003.10-2005.12$ & $A$ & $\mathrm{AF}$ & 29 & - & $50-70$ & $3.6-5.0$ weeks \\
\hline$(2006)^{20}$ & & & $2-12$ & & & $\mathrm{CF}$ & 29 & - & $40-70$ & $4.0-7.0$ weeks \\
\hline Liu et al & $48-69$ & $\geq 70$ & $3-10$ & $2003.10-2005.12$ & B & $\mathrm{AF}$ & 29 & $28-33$ & $56-66$ & $28-33$ days \\
\hline$(2013)^{21}$ & & & $2-12$ & & & $\mathrm{CF}$ & 29 & $28-33$ & $56-66$ & $37-45$ days \\
\hline Zhuang et al & $46-77$ & $>60$ & - & $2003.4-2006.4$ & B & $\mathrm{AF}$ & 22 & 30 & 60 & 30 days \\
\hline$(2009)^{22}$ & & & & & & $\mathrm{CF}$ & 22 & 30 & 60 & 42 days \\
\hline Peng et al & $4 I-75$ & $>60$ & $\leq 7$ & $1987.3-9$ & B & $\mathrm{HF}$ & 27 & 34 & 51 & 23 days \\
\hline$(1996)^{23}$ & & & & & & $\mathrm{CF}$ & 27 & $30-35$ & $60-70$ & 6-7 weeks \\
\hline Meng & $\leq 70$ & $\geq 70$ & - & $2004.6-2008.12$ & B & $\mathrm{HF}$ & 28 & - & $61.0-73.2$ & 5-6 weeks \\
\hline$(20 I I)^{24}$ & & & & & & $\mathrm{CF}$ & 28 & - & $60-70$ & 6-7 weeks \\
\hline Guo et al & $47-76$ & $\geq 70$ & - & $2000.3-2004.3$ & B & $\mathrm{HF}$ & 26 & - & 65 & 5 weeks \\
\hline$(2011)^{25}$ & & & & & & $\mathrm{CF}$ & 39 & - & 70 & 7 weeks \\
\hline Chen and Lin & $31-76$ & $\geq 80$ & $\leq 7$ & $1997.8-1998.10$ & A & $\mathrm{HF}$ & 50 & 66 & 75.9 & $45-53$ days \\
\hline$(2007)^{26}$ & & & & & & $\mathrm{CF}$ & 50 & 33 & 66 & 45-52 days \\
\hline Zhao and & - & $\geq 70$ & $>3$ & $1995.1-1996.5$ & B & $\mathrm{HF}$ & 115 & - & 70 & - \\
\hline Guo $(2002)^{27}$ & & & & & & $\mathrm{CF}$ & 112 & - & 70 & - \\
\hline Huang and & $37-73$ & $\geq 90$ & $\leq 9$ & - & B & $\mathrm{HF}$ & 26 & 64 & 76.8 & 32 days \\
\hline Gao $(200 I)^{28}$ & & & & & & $\mathrm{CF}$ & 35 & 35 & 70 & 7 weeks \\
\hline Pei and Zhu & $32-77$ & $\geq 80$ & $\leq 8$ & | $986.1-1989.4$ & B & $\mathrm{HF}$ & 46 & 70 & 80.5 & 49-53 days \\
\hline$(2000)^{29}$ & & & & & & $\mathrm{CF}$ & 46 & 35 & 70.0 & 47-56 days \\
\hline Xie and Shi & $\leq 70$ & $\geq 70$ & - & - & A & CAHF & 11 & 44 & 66 & 29-30 days \\
\hline$(1999)^{30}$ & & & & & & $\mathrm{CF}$ & 11 & 38 & 68.4 & $52-56$ days \\
\hline Ke et al & $38-76$ & $\geq 70$ & $\leq 10$ & 2005.I-2007.I & B & $\mathrm{CAHF}$ & 30 & - & 66 & 4.4 weeks \\
\hline$(2012)^{31}$ & & & & & & $\mathrm{CF}$ & 30 & - & 66 & 6.6 weeks \\
\hline Zhu et al & $38-76$ & $\geq 60$ & $\leq 10$ & 2004.I-2005.I & B & $\mathrm{CAHF}$ & 30 & - & 66 & 4.4 weeks \\
\hline$(2010)^{32}$ & & & & & & $\mathrm{CF}$ & 30 & - & 66 & 6.6 weeks \\
\hline Wang & $<70$ & $\geq 60$ & $\leq 7$ & $2006.7-2007.12$ & B & CAHF & 12 & - & $66-70$ & - \\
\hline$(2008)^{33}$ & & & & & & $\mathrm{CF}$ & 14 & - & $55-70$ & 5.5-7 weeks \\
\hline Li et al & $<70$ & $\geq 60$ & $\leq 8$ & $1990.10-1992.5$ & B & CAHF & 48 & - & 54 & 3.5 weeks \\
\hline$(2003)^{34}$ & & & & & & $\mathrm{CF}$ & 50 & - & $60-70$ & 6-7 weeks \\
\hline Zhang et al & $\leq 70$ & $\geq 70$ & $\leq 6$ & $1994.10-1998.5$ & B & CAHF & 39 & - & $60-70$ & $4.5-6$ weeks \\
\hline$(2002)^{35}$ & & & & & & $\mathrm{CF}$ & 37 & - & $60-66$ & 6-7 weeks \\
\hline Peng et al & $\leq 70$ & $\geq 70$ & $\leq 8$ & $1989.5-1994.12$ & B & CAHF & 106 & $34-40$ & $5 I-60$ & $3.3-4.0$ weeks \\
\hline$(2001)^{36}$ & & & & & & $\mathrm{CF}$ & 110 & $30-35$ & $60-70$ & 6-7 weeks \\
\hline Fan et al & $<70$ & $\geq 60$ & $\leq 8$ & $1990.12-1992.7$ & B & $\mathrm{CAHF}$ & 48 & - & 54 & 3.5 weeks \\
\hline$(2000)^{37}$ & & & & & & $\mathrm{CF}$ & 48 & $30-35$ & $60-70$ & 6-7 weeks \\
\hline \multirow[t]{2}{*}{ Yang $(20 \mathrm{II})^{38}$} & - & $\geq 70$ & $\leq 7$ & $2003.5-2007.6$ & A & $\mathrm{CAHF}+\mathrm{CT}$ & 100 & $40-45$ & $60-67.5$ & 4-4.5 weeks \\
\hline & & & & & & $\mathrm{CF}+\mathrm{CT}$ & 100 & $30-35$ & $60-70$ & 6-7 weeks \\
\hline Qian et al & $<70$ & $>80$ & $<8$ & $1992.6-1993.12$ & B & CAHF & 34 & 23 & $65 \pm 1.6$ & 34 days \\
\hline$(2000)^{39}$ & & & & & & $\mathrm{CF}$ & 35 & 33 & $65 \pm 2.1$ & 45 days \\
\hline
\end{tabular}

Notes: “-”, not mentioned. Data presented as n, range, or mean \pm standard deviation. *Inclusion periods shown as 'year.month' (eg, 2003.I0 is October 2003).

Abbreviations: AF, accelerated fractionation; CAHF, continuous accelerated hyperfractionation; CF, conventional fractionation; CT, chemotherapy; HF, hyperfractionation; KPS, Karnofsky performance scale.

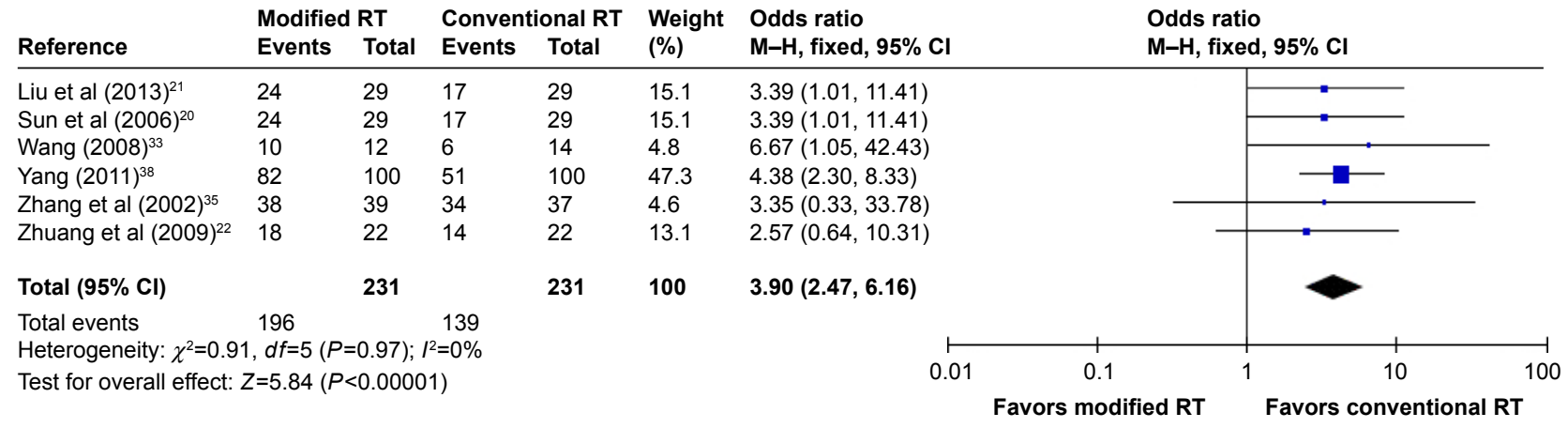

Figure 2 Forest plot comparing response rate between modified RT and conventional RT.

Abbreviations: $\mathrm{Cl}$, confidence interval; $\mathrm{M}-\mathrm{H}$, Mantel-Haenszel; RT, radiotherapy. 
A

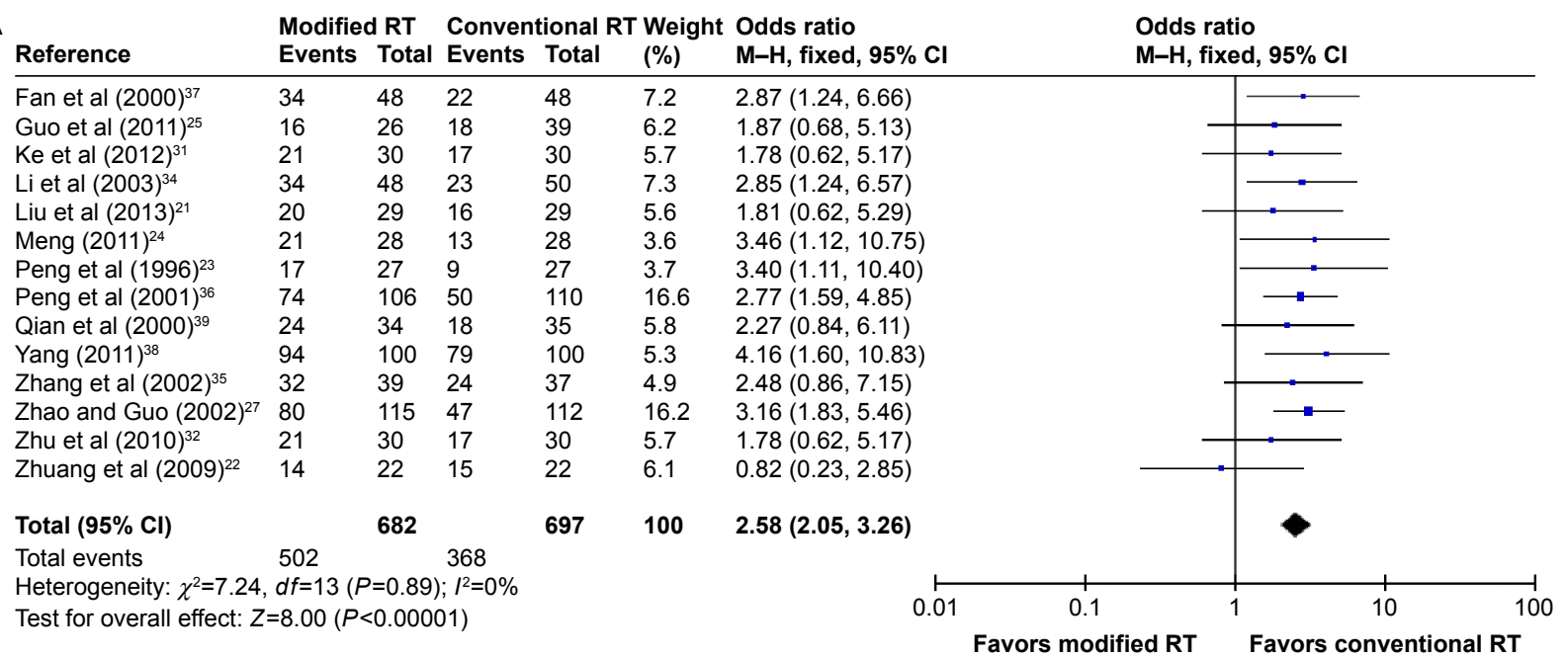

B

Reference

Modified RT Conventional RT Weight Odds ratio

Fan et al (2000) $)^{37}$

Guo et al $(2011)^{25}$

Ke et al (2012)

$\mathrm{Li}$ et al $(2003)^{34}$

Liu et al (2013) ${ }^{21}$

Meng $(2011)^{24}$

Pei and Zhu $(2000)^{29}$

Peng et al $(1996)^{23}$

Peng et al $(2001)^{36}$

Qian et al $(2000)^{39}$

Yang $(2011)^{38}$

Zhang et al $(2002)^{35}$

Zhao and Guo (2002) $)^{27} 47$

Zhu et al $(2010)^{32}$

Zhuang et al (2009) ${ }^{22}$

Total $(95 \% \mathrm{Cl})$ Events Total Events Total

Total events $\quad 296 \quad 171$

Test for overall effect: $Z=7.19(P<0.00001)$

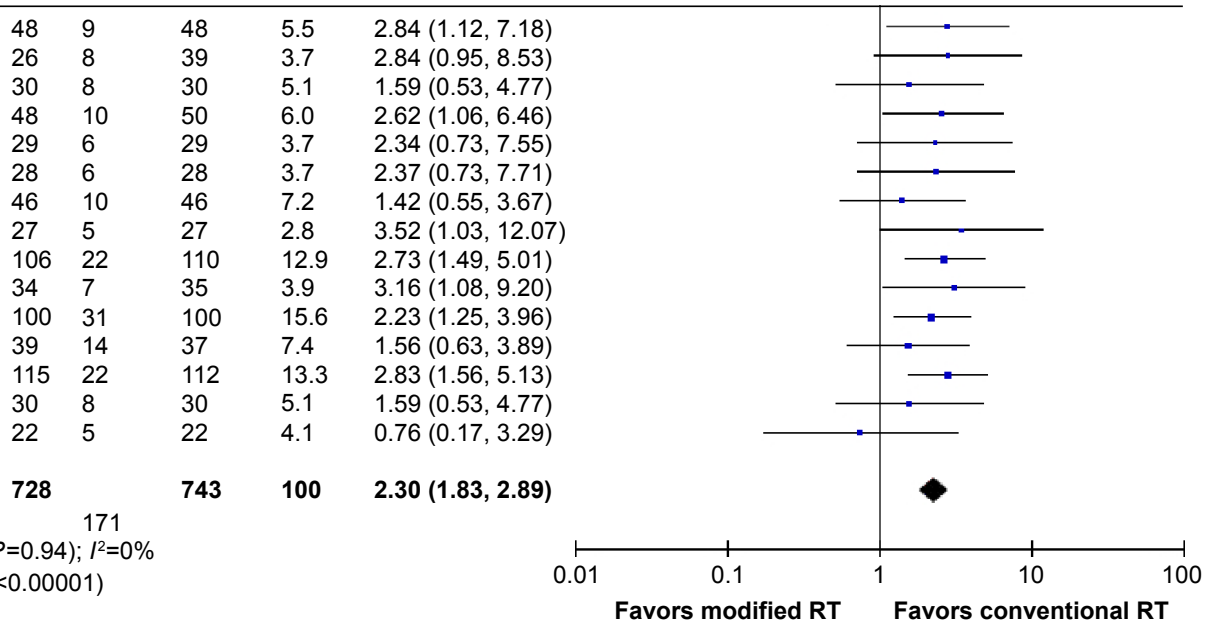

C

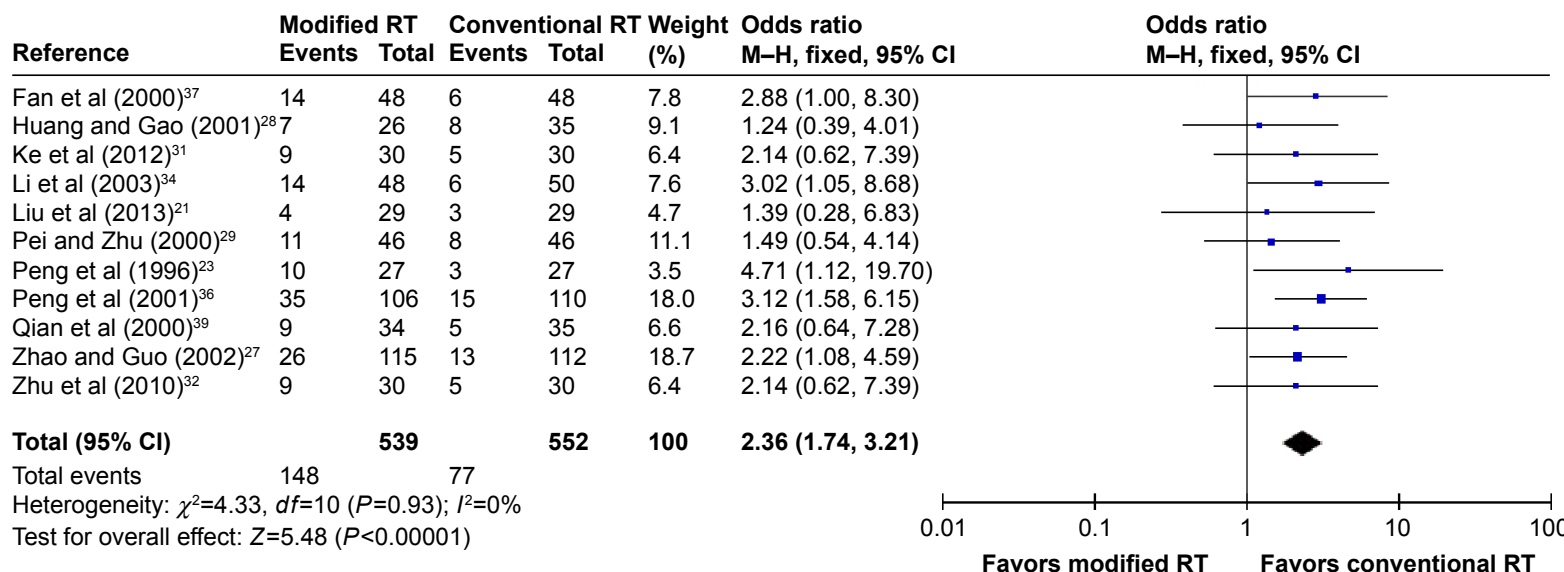

Figure 3 Forest plots comparing survival rate between modified RT and conventional RT: (A) I-year survival; (B) 3-year survival; (C) 5-year survival.

Abbreviations: $\mathrm{Cl}$, confidence interval; $\mathrm{M}-\mathrm{H}$, Mantel-Haenszel; $\mathrm{RT}$, radiotherapy.

95\% CI: $1.83-2.89, P<0.001)$. The fixed-effect model was used to summarize the studies, as there was no evidence of heterogeneity between two arms ( $P=0.94, I^{2}=0.0 \%$; Figure $3 \mathrm{~B})$. For the 5-year survival, there was strong evidence, based on 11 studies, indicating that patients benefited from the modified RT (OR $=2.36,95 \%$ CI: $1.74-3.21$, $P<0.001)$. Analysis of heterogeneity indicated that there was no heterogeneity among the included trials $(P=0.93$, 
$I^{2}=0.0 \%$ ). Therefore, the fixed-effect model was used to analyze the summary OR (Figure 3C).

The results of the 1-year local control rate based on 6 studies suggested an obvious advantage for the modified RT group $(\mathrm{OR}=2.46,95 \% \mathrm{CI}: 1.72-3.51, P<0.001$; Figure 4A). For the 3 -year local control rate, the meta-analysis based on 7 trials showed a statistically significant difference that favored the modified RT group $(\mathrm{OR}=2.08$, 95\% CI: 1.49-2.90, $P<0.001$; Figure 4B). For the 5-year local control rate, the results from 5 RCTs indicated that the modified RT improved the 5-year local control rate (OR $=2.15$, 95\% CI: 1.38-3.34, $P<0.001$; Figure 4C). The heterogeneity analysis for the 1-, 3- and 5-year local control suggested that there was no heterogeneity among the included RCTs $(P=0.50, P=0.91$ and $P=0.97$, respectively $)$.
Therefore, the fixed-effect models were selected to analyze the pooled ORs.

\section{Acute toxicity}

Fifteen trials were included in the evaluation of acute radiation esophagitis and 13 trials in the evaluation of acute radiation tracheitis. The occurrences of acute radiation esophagitis and tracheitis were higher in the modified RT group than in the conventional RT group, with an OR value of $1.70(95 \%$ CI: 1.27-2.28, $P<0.001)$ and 1.47 (95\% CI: 1.09-1.99, $P=0.01)$, respectively. No evidence of heterogeneity was detected for acute radiation esophagitis $\left(P=0.55, I^{2}=0.0 \%\right)$ or acute radiation tracheitis ( $P=0.44, I^{2}=1.0 \%$; Figure 5).

Eight RCTs were available to evaluate the early adverse reactions (esophageal perforation and esophagorrhagia).

A

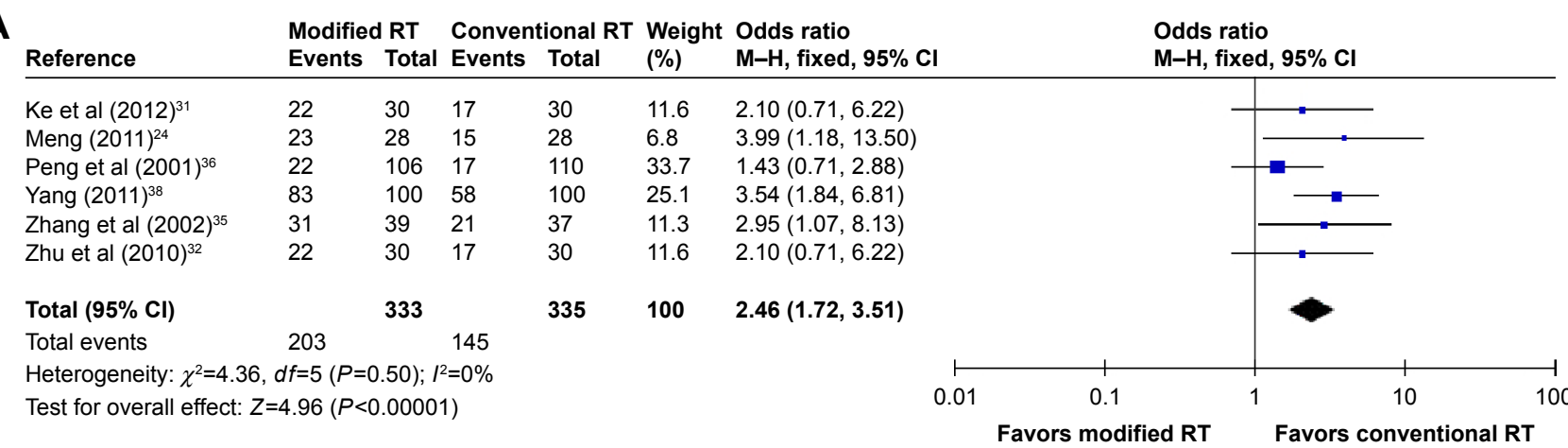

B

Reference

Modified RT Conventional RT Weight Odds ratio

Ke et al (2012) ${ }^{31}$ Meng (2011) ${ }^{24}$

Pei and Zhu $(2000)^{29}$

Peng et al (2001) ${ }^{36}$

Yang $(2011)^{38}$

Zhang et al $(2002)^{35}$

Zhu et al (2010) ${ }^{32}$

Events Total Events Total

(\%) $\quad \mathrm{M}-\mathrm{H}$, fixed, $95 \% \mathrm{Cl}$

Odds ratio

\begin{tabular}{|c|c|c|c|c|}
\hline 16 & 30 & 30 & 10.7 & $1.97(0.70,5.54)$ \\
\hline 13 & 28 & 28 & 6.7 & $3.18(0.99,10.23)$ \\
\hline 26 & 46 & 46 & 13.6 & $2.69(1.15,6.28)$ \\
\hline 16 & $106 \quad 11$ & 110 & 19.1 & $1.60(0.71,3.63)$ \\
\hline 31 & $100 \quad 16$ & 100 & 23.0 & $2.36(1.19,4.67)$ \\
\hline 18 & 39 & 37 & 16.1 & $1.41(0.56,3.52)$ \\
\hline 16 & 30 & 30 & 10.7 & $1.97(0.70,5.54)$ \\
\hline & 379 & 381 & 100 & $2.08(1.49,2.90)$ \\
\hline
\end{tabular}

Total $(95 \% \mathrm{Cl})$

$136 \quad 84$

Heterogeneity: $\chi^{2}=2.10, d f=6(P=0.91) ; I^{2}=0 \%$

Test for overall effect: $Z=4.27(P<0.0001)$

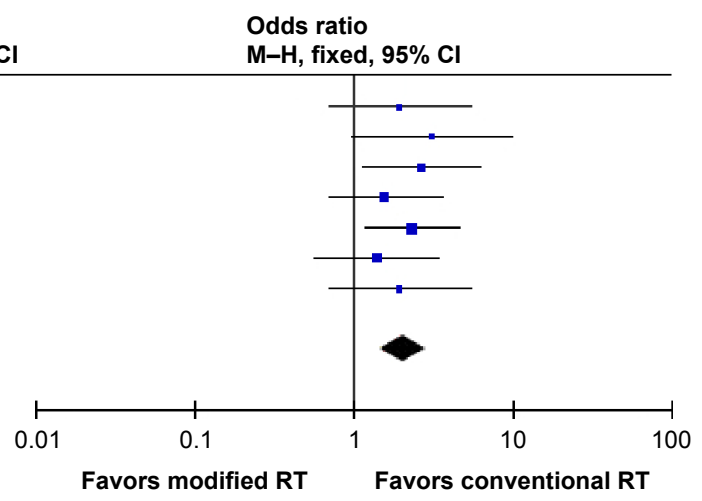

C

Reference

Modified RT Conventional RT Weight Odds ratio

Huang and Gao (2001) 14

Ke et al (2012) 31

Pei and Zhu $(2000)^{29} \quad 24$

Peng et al (2001) $)^{36} \quad 13$

Zhu et al (2010) 32

vents Total Events Total

(\%) $\mathrm{M}-\mathrm{H}$, fixed, $95 \% \mathrm{Cl}$

Odds ratio

\begin{tabular}{|c|c|c|c|c|}
\hline 26 & 13 & 35 & 18.7 & $1.97(0.70,5.54)$ \\
\hline 30 & 8 & 30 & 16.6 & $2.10(0.71,6.22)$ \\
\hline 46 & 13 & 46 & 22.8 & $2.77(1.17,6.57)$ \\
\hline 106 & 8 & 110 & 25.2 & $1.78(0.71,4.49)$ \\
\hline 0 & 8 & 30 & 16.6 & $2.10(0.71,6.22)$ \\
\hline & & 251 & 100 & $2.15(1.38,3.34)$ \\
\hline
\end{tabular}

Total $(95 \% \mathrm{Cl})$

238

251

Total events $\quad 77 \quad 50$

Heterogeneity: $\chi^{2}=0.52, d f=4(P=0.97) ; I^{2}=0 \%$

Test for overall effect: $Z=3.41(P=0.0007)$

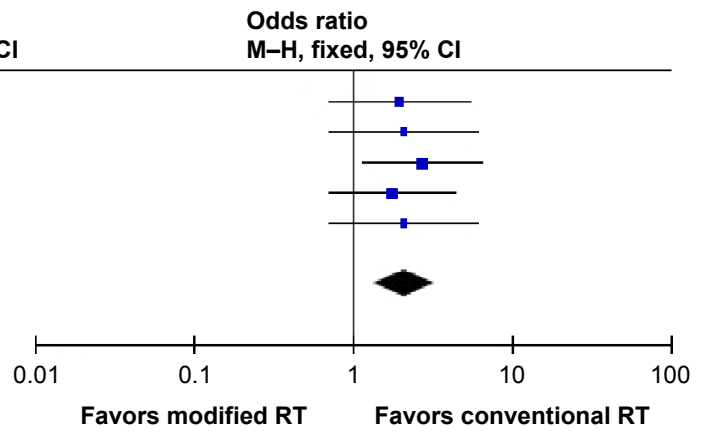

Figure 4 Forest plots comparing local control rate between modified RT and conventional RT: (A) I-year local control; (B) 3-year local control; (C) 5-year local control. Abbreviations: $\mathrm{Cl}$, confidence interval; $\mathrm{M}-\mathrm{H}$, Mantel-Haenszel; RT, radiotherapy. 


\begin{tabular}{|c|c|c|c|c|}
\hline \multirow[b]{2}{*}{ Reference } & \multicolumn{2}{|c|}{ Modified RT } & \multicolumn{2}{|c|}{ Conventional RT } \\
\hline & Events & Total & Events & Total \\
\hline Chen and Lin $(2007)^{26}$ & 12 & 50 & 14 & 50 \\
\hline Fan et al $(2000)^{37}$ & 10 & 48 & 7 & 48 \\
\hline Guo et al $(2011)^{25}$ & 18 & 26 & 21 & 39 \\
\hline Huang and Gao $(2001)^{28}$ & 9 & 26 & 3 & 35 \\
\hline Ke et al $(2012)^{31}$ & 24 & 30 & 19 & 30 \\
\hline Li et al $(2003)^{34}$ & 10 & 48 & 7 & 50 \\
\hline Meng $(2011)^{24}$ & 10 & 28 & 9 & 28 \\
\hline Pei and Zhu $(2000)^{29}$ & 12 & 46 & 11 & 46 \\
\hline Qian et al $(2000)^{39}$ & 13 & 34 & 6 & 35 \\
\hline Sun et al $(2006)^{20}$ & 29 & 29 & 29 & 29 \\
\hline Wang $(2008)^{33}$ & 11 & 12 & 12 & 14 \\
\hline Xie and Shi $(1999)^{30}$ & 11 & 11 & 6 & 11 \\
\hline Zhao and Guo $(2002)^{27}$ & 25 & 115 & 18 & 112 \\
\hline Zhu et al $(2010)^{32}$ & 24 & 30 & 19 & 30 \\
\hline Zhuang et al $(2009)^{22}$ & 22 & 22 & 22 & 22 \\
\hline \multicolumn{2}{|l|}{ Total $(95 \% \mathrm{Cl})$} & \multicolumn{2}{|l|}{555} & 579 \\
\hline & 240 & & 203 & \\
\hline \multicolumn{5}{|c|}{ Heterogeneity: $\chi^{2}=10.78, d f=12(P=0.55) ; I^{2}=0 \%$} \\
\hline \multicolumn{5}{|c|}{ Test for overall effect: $Z=3.55(P=0.0004)$} \\
\hline
\end{tabular}

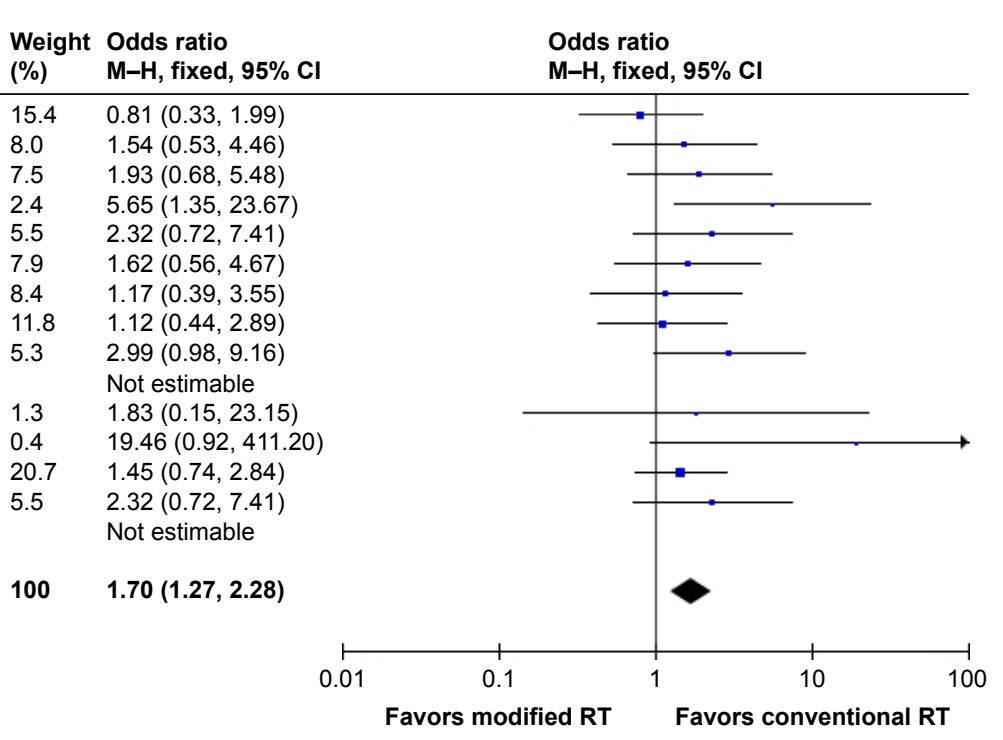

B

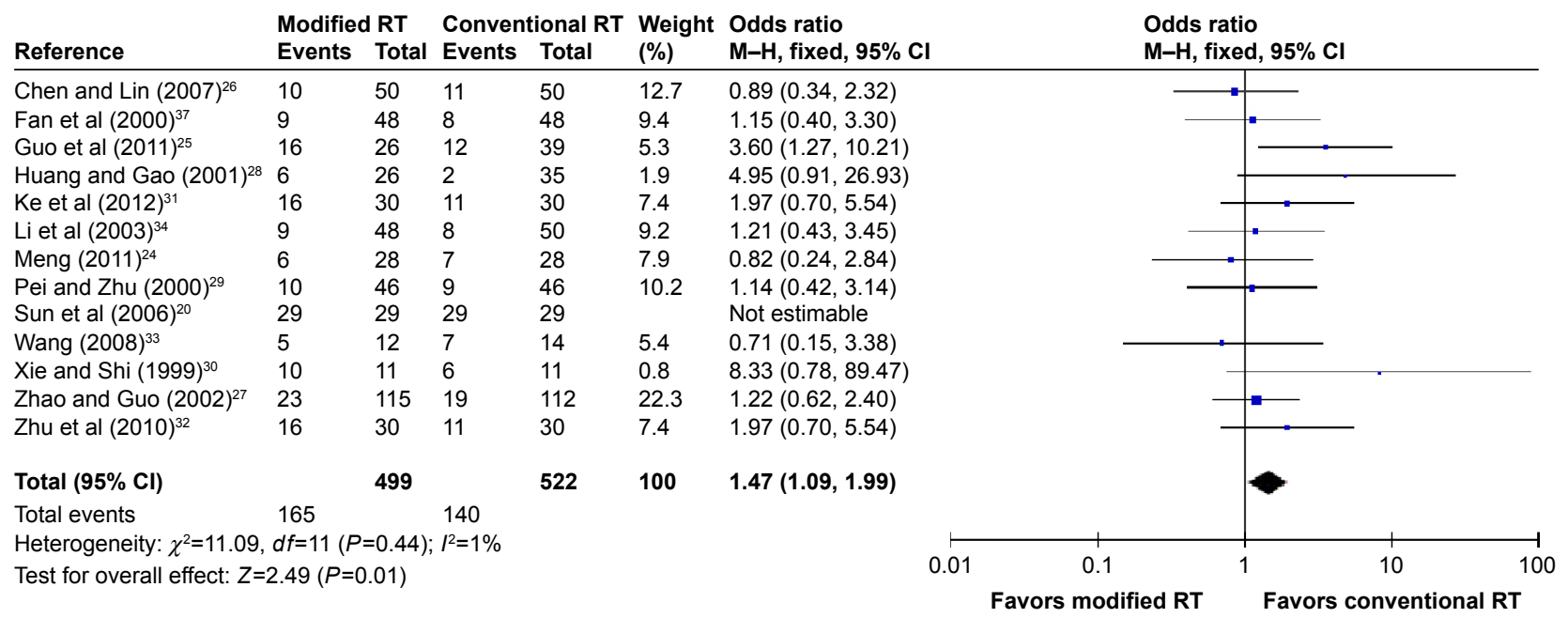

Figure 5 Forest plots comparing acute radiation reactions between modified RT and conventional RT: (A) acute radiation esophagitis; (B) acute radiation tracheitis. Abbreviations: $\mathrm{Cl}$, confidence interval; $\mathrm{M}-\mathrm{H}$, Mantel-Haenszel; $\mathrm{RT}$, radiotherapy.

A fixed-effect model was selected for the pooled analysis because no evidence of heterogeneity was found $(P=0.67$, $I^{2}=0.0 \% ; P=0.86, I^{2}=0.0 \%$ ). There was no observed statistically significant difference between the two arms, with an OR value of 1.30 (95\% CI: $0.51-3.32, P=0.58)$ and $0.88(95 \%$ CI: $0.41-1.88, P=0.74$ ), respectively (Figure 6).

\section{Publication bias and sensitivity analyses}

The publication biases were presented by funnel plots and examined by Egger's tests. Publication bias was found only in the analysis of acute esophagitis ( $t=2.43, P=0.03$; Table 2$)$.

Sensitivity analyses were performed to evaluate the stability of our meta-analysis. The results of these analyses showed that the data in this meta-analysis were relatively stable, with low sensibility.

\section{Discussion}

Esophageal carcinomas are characterized by a high mortality rate. RT has become an important treatment method in the multidisciplinary management of esophageal cancer. Presently, the majority of clinical practices have suggested that the failure of malignant tumor treatment by CF RT is primarily due to local recurrence. Furthermore, Struikmans et $\mathrm{al}^{40}$ have also shown that the accelerated proliferation of living tumor stem cells during RT is a primary cause for failures in the treatment of squamous cell carcinoma of the digestive and upper respiratory tracts. Therefore, inhibition of the accelerated repopulation of the tumor stem cells is a key factor in improving the survival and local control rates. Even if the primary tumor is resectable, the survival rate remains very low as a result of both surgery-related complications 
A

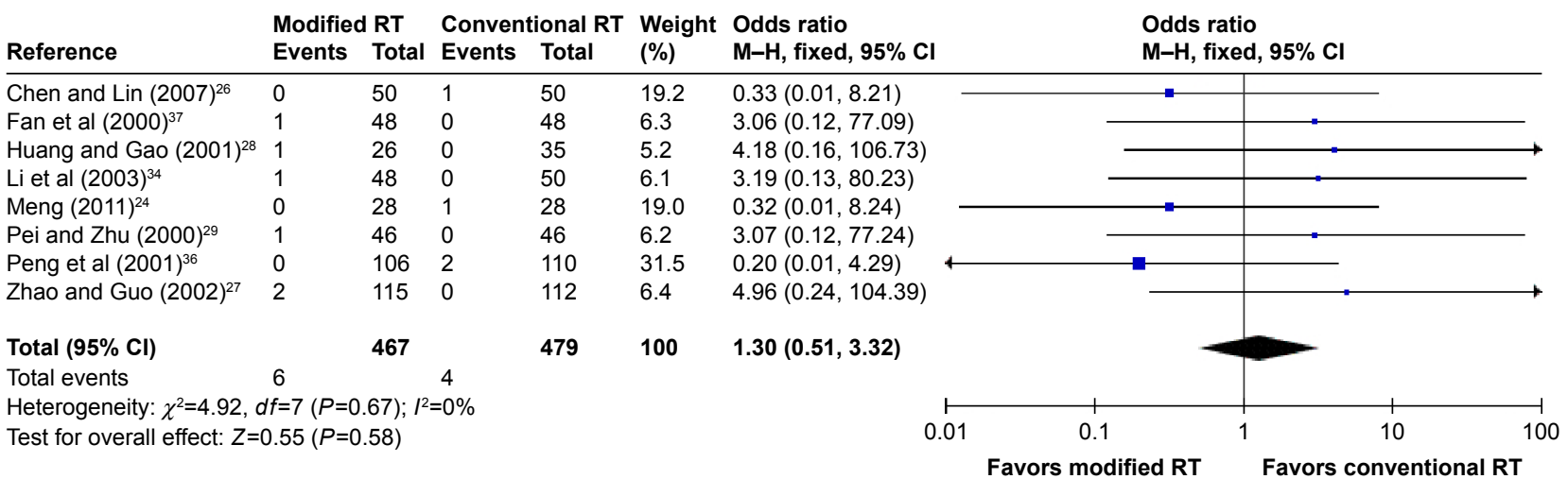

B

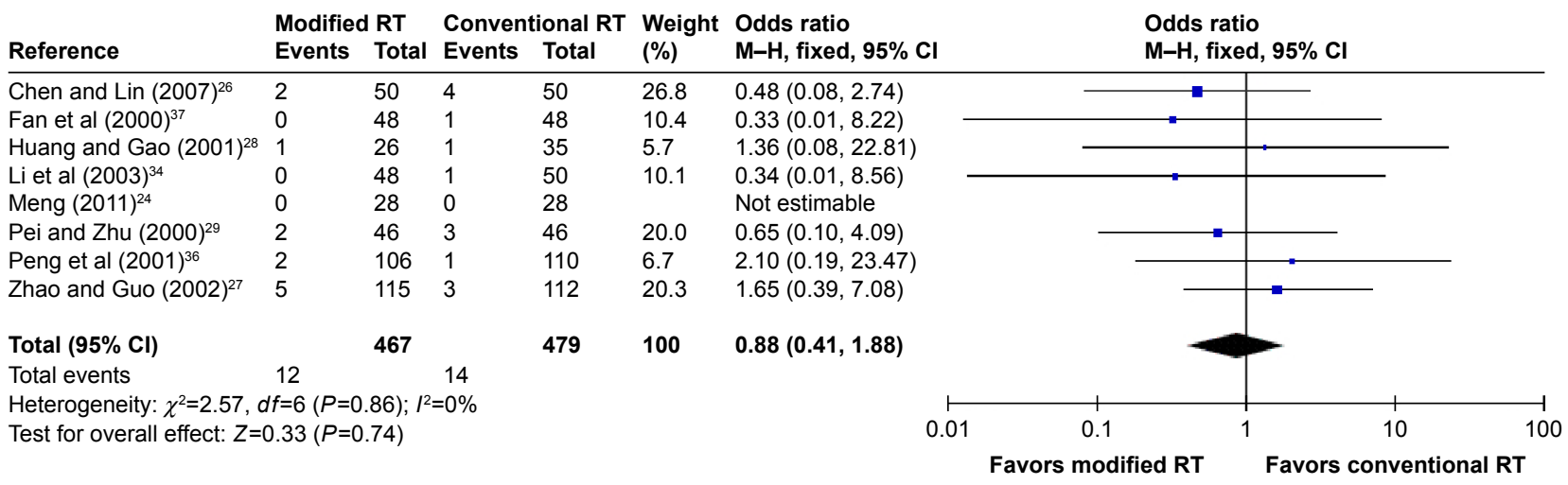

Figure 6 Forest plots comparing early adverse reactions between modified RT and conventional RT: (A) esophageal perforation; (B) esophagorrhagia. Abbreviations: $\mathrm{Cl}$, confidence interval; $\mathrm{M}-\mathrm{H}$, Mantel-Haenszel; RT, radiotherapy.

and early lymphatic and hematogenous dissemination; this is especially true for squamous tumors in which the primary tumor has invaded the adventitia or adjacent structures (T3-T4). ${ }^{41}$ In addition, the potential doubling time of the tumor is closely related to accelerated multiplication. Moreover, the length of time required for CF RT may be unfavorable when treating a proliferating tumor. Shortening the total treatment time may improve the local control rate of the tumor. ${ }^{42}$ Therefore, modified HF techniques can be applied and continue to be developed.

Table 2 Publication biases assessment of this meta-analysis

\begin{tabular}{lll}
\hline Outcome & $\begin{array}{l}\text { Egger's test } \\
(\boldsymbol{t} \text {-value })\end{array}$ & $\boldsymbol{P}$-value \\
\hline Response rate & -0.16 & 0.88 \\
One-year survival & -0.49 & 0.64 \\
Three-year survival & -1.03 & 0.32 \\
Five-year survival & -0.92 & 0.38 \\
One-year local control & -0.79 & 0.47 \\
Three-year local control & -0.35 & 0.74 \\
Five-year local control & -1.20 & 0.32 \\
Acute esophagitis & 2.43 & 0.03 \\
Acute tracheitis & 1.04 & 0.33 \\
Esophageal perforation & 0.33 & 0.75 \\
Esophagorrhagia & 0.23 & 0.83 \\
\hline
\end{tabular}

Various schedules of HF and AF of RT in randomized clinical trials have proven to be superior to standard fractionation in multiple tumor types and sites. However, it is likely that the findings regarding acute toxicity have limited the widespread adoption of this approach. In regard to head and neck cancer, a meta-analysis suggested that there was a significant benefit with OS and locoregional control (LRC) at 5 years for hyperfractionated and/or accelerated RT. ${ }^{13}$ HF improved the LRC by $8 \%-20 \%$ in the treatment of head and neck cancer. ${ }^{43-46}$ Perhaps the largest trial of AF versus $\mathrm{CF}$, which included 1,485 patients in Denmark, reported a better overall 5-year LRC and disease-specific survival for the former; however, it also reported a worse acute morbidity, and there were no statistically significant differences in OS and late toxicity. ${ }^{47}$ In lung cancer, regardless of whether it was non-small-cell lung cancer or small-cell lung cancer, an individual patient data meta-analysis showed that either hyperfractionated or accelerated RT improved OS with an absolute benefit of $2.5 \%$ at 5 years, but increased the risk of acute esophageal toxicity. ${ }^{14}$ Similar results were also found with bladder cancer. ${ }^{15,16}$ Modified RT has also been used to treat patients with sarcoma. Donaldson et $\mathrm{al}^{17}$ noted that a higher acute toxicity was found for HF in the treatment of rhabdomyosarcoma in children. 
To the best of our knowledge, this meta-analysis is the first to evaluate the efficacy and safety of accelerated and/or hyperfractionated RT in the treatment of patients with esophageal carcinoma, compared with conventional RT. The included trials of this meta-analysis showed conflicting results on the efficacy and safety of modified RT. In contrast to the results of this study, some of the included studies suggested that the differences in the survival rates and acute toxicity between the modified and the conventional RT groups in patients with esophageal cancer were not statistically significant. The results of this study showed that the accelerated and/or hyperfractionated RT group had an improved response rate, 1-, 3- and 5-year survival, and 1-, 3- and 5-year local control rate in the treatment of esophageal carcinoma, compared with the conventional RT group. With $\mathrm{AF}$, the total fraction is delivered over a shorter number of elapsed days, and with HF, the daily dose is decreased, but there is an increased number of overall treatment dose. The theoretical advantage of this regimen is a decreased opportunity for tumor proliferation to occur during treatment by shortening the overall treatment time. Some reports have suggested that accelerated regeneration always begins at 3-5 weeks after the beginning of RT. At the same time, an increased daily dose should be an effective way to overcome tumor repopulation. The reduction in total treatment time decreases the opportunity for tumor cells to repopulate during RT treatment and, therefore, increases the probability of tumor control with a given total dose. .8,49 $^{40}$ The data for acute toxicity were also available in this metaanalysis. The overall OR indicated that altered RT increased the incidence of acute radiation reactions, such as radiation esophagitis and tracheitis, which were the primary acute side effects occurring during RT for esophageal cancer. Possible explanations for these results are that the altered RT may increase the total dose of RT and shorten the total treatment time, which is related to the occurrence of acute radiation esophagitis and tracheitis, whereas the RT time and dose in conventional RT are more in line with the biologic characteristics of $\mathrm{RT},{ }^{50}$ allowing sufficient time for the repair for related organs and tissues. However, there was no observed statistically significant difference in the early adverse reactions (esophageal perforation and esophagorrhagia) in this meta-analysis. Further observations with an expanded sample size are needed.

The randomized trials assessing hyperfractionated and/ or accelerated RT in esophageal cancer appear to offer clearer results for their efficacy and safety. However, there are several potential limitations to our meta-analysis. First, eligible studies were limited because the RCTs included in this meta-analysis focusing on Chinese patients lacked sufficient statistical power; none of these studies were multicenter clinical trials or multinational samples. Second, most of the 20 studies included a low number of patients, and only 3 trials included more than 100 patients per arm. These low numbers are the reason that it was advantageous and statistically significant for this meta-analysis to use statistical methods to pool the results of individual studies, thereby expanding the sample size. Third, the long-term toxicity data are inaccessible. The adoption of these various schedules of RT depends on the accurate reporting of long-term results. Therefore, for clinicians to be confident in using a specific RT schedule, the long-term toxicity profiles require further clinical research and discussion. Fourth, we compared only the different RT methods and did not take into account their combination with CT. Combination modified RT and CT should be tested for its efficacy and safety in esophageal cancer in the future.

\section{Conclusion}

In Chinese patients with squamous cell esophagus carcinoma, a significant benefit was obtained with modified fractionation RT, suggesting that the appropriateness of its use be reinforced in clinical practice.

\section{Disclosure}

The authors report no conflicts of interest in this work.

\section{References}

1. Ferlay J, Shin HR, Bray F, Forman D, Mathers C, Parkin DM. Estimates of worldwide burden of cancer in 2008: GLOBOCAN 2008. Int J Cancer. 2010;127(12):2893-2917.

2. Tran GD, Sun XD, Abnet CC, et al. Prospective study of risk factors for esophageal and gastric cancers in the Linxian general population trial cohort in China. Int J Cancer. 2005;113(3):456-463.

3. Gholipour C, Shalchi RA, Abbasi M. A histopathological study of esophageal cancer on the western side of the Caspian littoral from 1994 to 2003. Dis Esophagus. 2008;21(4):322-327.

4. Andrici J, Eslick GD. Hot food and beverage consumption and the risk of esophageal cancer: a meta-analysis. Am J Prev Med. 2015; 49(6):952-960.

5. Mariette C, Piessen G, Triboulet JP. Therapeutic strategies in oesophageal carcinoma: role of surgery and other modalities. Lancet Oncol. 2007;8(6):545-553.

6. Hishikawa Y, Kurisu K, Taniguchi M, Kamikonya N, Miura T. High-dose-rate intraluminal brachytherapy for esophageal cancer: 10 years experience in Hyogo College of Medicine. Radiother Oncol. 1991;21(2):107-114.

7. Yamada S, Takai Y, Nemoto K, et al. Low-dose rate telecobalt therapy as a boost against esophageal carcinomas. Cancer. 1992;69(5): 1099-1103.

8. Brenner B, Ilson DH, Minsky BD. Treatment of localized esophageal cancer. Semin Oncol. 2004;31(4):554-565.

9. Peters LJ, Ang KK. The role of altered fractionation in head and neck cancers. Semin Radiat Oncol. 1992;2(3):180-194.

10. Arriagada R, Komaki R, Cox JD. Radiation dose escalation in non-small cell carcinoma of the lung. Semin Radiat Oncol. 2004;14(4):287-291.

11. Ahmed KA, Correa CR, Dilling TJ, et al. Altered fractionation schedules in radiation treatment: a review. Semin Oncol. 2014;41(6):730-750. 
12. Mallick S, Benson R, Julka PK, Rath GK. Altered fractionation radiotherapy in head and neck squamous cell carcinoma. J Egypt Natl Canc Inst. 2016;28(2):73-80.

13. Bourhis J, Overgaard J, Audry H, et al. Hyperfractionated or accelerated radiotherapy in head and neck cancer: a meta-analysis. Lancet. 2006;368(9538):843-854.

14. Mauguen A, Le Pechoux C, Saunders MI, et al. Hyperfractionated or accelerated radiotherapy in lung cancer: an individual patient data meta-analysis. J Clin Oncol. 2012;30(22):2788-2797.

15. Edsmyr F, Andersson L, Esposti PL, Littbrand B, Nilsson B. Irradiation therapy with multiple small fractions per day in urinary bladder cancer. Radiother Oncol. 1985;4(3):197-203.

16. Naslund I, Nilsson B, Littbrand B. Hyperfractionated radiotherapy of bladder cancer. A ten-year follow-up of a randomized clinical trial. Acta Oncol. 1994;33(4):397-402.

17. Donaldson SS, Meza J, Breneman JC, et al. Results from the IRS-IV randomized trial of hyperfractionated radiotherapy in children with rhabdomyosarcoma - a report from the IRSG. Int J Radiat Oncol Biol Phys. 2001;51(3):718-728.

18. Eisenhauer EA, Therasse P, Bogaerts J, et al. New response evaluation criteria in solid tumours: revised RECIST guideline (version 1.1). Eur J Cancer. 2009;45(2):228-247.

19. Higgins JP, Green S. Cochrane Handbook For Systematic Reviews Of Interventions (Version 5.0.0); 2009.

20. Sun SP, Liu YZ, Ye T, et al. Randomized clinical trial on seven-dayper-week continuous accelerated irradiation for patients with esophageal carcinoma: Preliminary report on tumor response and acute toxicity. World Journal of Gastroenterology. 2006;12(43):7047-7050.

21. Liu YZ, Sun SP, Ye T, et al. [Clinical efficacy of seven-days continuous accelerated irradiation for patients with esophageal carcinoma]. Chinese Journal of Clinical Medicine. 2013;26(4):320-323. Chinese.

22. Zhuang XB, Qiao TK, Chen W, Li RR. [Clinical observation of esophageal carcinoma treated with 7-days continuous accelerated irradiation]. Chinese Journal of Clinical Medicine. 2009;16(2):217-219. Chinese.

23. Peng HG, Liu H, Wang YJ, Jiang H, Ren KJ. [Study of hyperfractionated irradiation in the treatment of esophageal carcinoma]. Chinese Journal of Clinical Oncology. 1996;23(7):461-463. Chinese.

24. Meng CY. [Clinical observation of hyperfractionated radiotherapy for esophageal cancer patients]. China Medical Herald. 2011;8(8):41-43. Chinese.

25. Guo H, Xie CS, Liu LH, Fang YH, Sun XW. [The survival rate and effect of esophageal hyperfractioned radiotherapy and conventional radiotherapy]. China Medical Herald. 2011;8(23):26-27. Chinese.

26. Chen JX, Lin LR. [Long term efficacy of hyperfractionated radiotherapy for esophageal carcinoma]. China Practical Medicine. 2007;2(3): 35-36. Chinese.

27. Zhao Y, Guo YH. [115 cases of hyperfractionated radiotherapy for esophageal cancer]. Journal of Cancer Control and Treatment. 2002; 15(1):21-22. Chinese.

28. Huang MD, Gao JH. [The efficacy and complications of hyperfractionated radiotherapy and conventional fractionated radiotherapy for esophageal cancer]. Chinese Journal of Misdiagnostics. 2001;1(9):1345-1346. Chinese.

29. Pei HL, Zhu YH. [Long term results of hyperfractionation radiotherapy for esophageal carcinoma]. Chin J Radiat Oncol. 2000;9(1):23-25. Chinese.

30. Xie L, Shi XH. [Acute toxic effect of accelerated hyperfractionation radiotherapy]. Chinese Journal of Clinical Oncology. 1999;26(1):12-15. Chinese.

31. Ke LY, Huang BY, Cheng YL. [Therapeutic effects report of whole course accelerated hyperfractionation for esophageal cancer]. China Medical Engineering. 2012;20(5):10-11. Chinese.

32. Zhu GJ, Zhao X, Zong CD. [Therapeutic effects report of whole course accelerated hyperfractionation for esophageal cancer]. World Journal of Tumor. 2010;9(2):115-117. Chinese.
33. Wang D. [Clinical observation of conventional radiotherapy and whole course accelerated fractionation radiotherapy for esophageal carcinoma]. Nei Mongol Journal of Traditional Chinese Medicine. 2008; 27(22):51. Chinese.

34. Li GW, Guo YZ, Guo YX, et al. [Accelerated fractionation radiotherapy for esophageal carcinoma]. Henan Medical Research. 2003;12(1): 45-47. Chinese.

35. Zhang BH, Su CL, Liu HY, Zhang YY, Zhang YL, Gong LP. [Accelerated hypertractionation radiotherapy using the field-in-field technique for upper thoracic esophageal carcinoma]. Chon J Radiat Oncol. 2002; 11(2):101-103. Chinese.

36. Peng KG, Duan SM, Liu H, Jiang H, Wang YJ. [Whole course accelerated hyperfractionation radiotherapy for esophageal carcinoma]. Chinese Journal of Radiation Oncology. 2001;10(2):77-79. Chinese.

37. Fan RT, Guo YX, Guo YZ, Li GW, Shi GZ. [Toxic effect and complication of accelerated hyperfractionation for esophageal carcinoma]. Chinese Journal of Cancer. 2000;19(6):597-599. Chinese.

38. Yang Z. [Whole course accelerated hyperfractionation with three dimensional conformal radiotherapy for esophageal carcinoma]. Medical Information. 2011;24(4):758-759. Chinese.

39. Qian M, Hao JF, Liu XQ, Wei GS. [Long term results of accelerated hyperfraction field-in-field radiotherapy for middle esophageal carcinoma]. Chinese Journal of Clinical Oncology and Rehabilitation. 2000; 7(5):36-37. Chinese.

40. Struikmans H, Kal HB, Hordijk GJ, van der Tweel I. Proliferative capacity in head and neck cancer. Head neck. 2001;23(6):484-491.

41. Siewert JR, Stein HJ, Feith M, Bruecher BL, Bartels H, Fink U. Histologic tumor type is an independent prognostic parameter in esophageal cancer: lessons from more than 1,000 consecutive resections at a single center in the Western world. Ann Surg. 2001;234(3):360-367; discussion 368-369.

42. Skladowski K, Maciejewski B, Golen M, Pilecki B, Przeorek W, Tarnawski R. Randomized clinical trial on 7-day-continuous accelerated irradiation (CAIR) of head and neck cancer - report on 3-year tumour control and normal tissue toxicity. Radiother Oncol. 2000; 55(2): 101-110

43. Horiot JC, Le Fur R, N'Guyen T, et al. Hyperfractionation versus conventional fractionation in oropharyngeal carcinoma: final analysis of a randomized trial of the EORTC cooperative group of radiotherapy. Radiother Oncol. 1992;25(4):231-241.

44. Fu KK, Pajak TF, Trotti A, et al. A Radiation Therapy Oncology Group (RTOG) phase III randomized study to compare hyperfractionation and two variants of accelerated fractionation to standard fractionation radiotherapy for head and neck squamous cell carcinomas: first report of RTOG 9003. Int J Radiat Oncol Biol Phys. 2000;48(1):7-16.

45. Pinto LH, Canary PC, Araujo CM, Bacelar SC, Souhami L. Prospective randomized trial comparing hyperfractionated versus conventional radiotherapy in stages III and IV oropharyngeal carcinoma. Int J Radiat Oncol Biol Phys. 1991;21(3):557-562.

46. Cummings B, Keane T, Pintilie M, et al. Five year results of a randomized trial comparing hyperfractionated to conventional radiotherapy over four weeks in locally advanced head and neck cancer. Radiother Oncol. 2007;85(1):7-16

47. Overgaard J, Hansen HS, Specht L, et al. Five compared with six fractions per week of conventional radiotherapy of squamous-cell carcinoma of head and neck: DAHANCA 6 and 7 randomised controlled trial. Lancet. 2003;362(9388):933-940.

48. Suit HD, Howes AE, Hunter N. Dependence of response of a $\mathrm{C} 3 \mathrm{H}$ mammary carcinoma to fractionated irradiation on fractionation number and intertreatment interval. Radiat Res. 1977;72(3):440-454

49. Peters LJ, Ang KK, Thames HD Jr. Accelerated fractionation in the radiation treatment of head and neck cancer. A critical comparison of different strategies. Acta Oncol. 1988;27(2):185-194.

50. Sun SP, Cheng NI. [Radio-biological basic and clinical application of unconventional fractionation radiotherapy]. Chinese J Cancer Prevention Treatment. 2007;14(3):226-229. Chinese. 
OncoTargets and Therapy

\section{Publish your work in this journal}

OncoTargets and Therapy is an international, peer-reviewed, open access journal focusing on the pathological basis of all cancers, potential targets for therapy and treatment protocols employed to improve the management of cancer patients. The journal also focuses on the impact of management programs and new therapeutic agents and protocols on

patient perspectives such as quality of life, adherence and satisfaction The manuscript management system is completely online and includes a very quick and fair peer-review system, which is all easy to use. Visit http://www.dovepress.com/testimonials.php to read real quotes from published authors.

Submit your manuscript here: http://www.dovepress.com/oncotargets-and-therapy-journal 